\title{
Intensive Pharmacologic Treatment in Patients With Acute Non ST-Segment Elevation Myocardial Infarction Who Did Not Undergo Percutaneous Coronary Intervention
}

\author{
Hae Chang Jeong, MD; Young Keun Ahn, MD; Myung Ho Jeong; Shung Chull Chae; Jong Hyun Kim; \\ In Whan Seong; Young Jo Kim; Seung Ho Hur; Dong Hoon Choi; Taek Jong Hong; Jung Han Yoon; \\ Jae Young Rhew; Jei Keon Chae; Doo Il Kim; In Ho Chae; Bon Kwon Koo; Byung Ok Kim; \\ Nae Hee Lee; Jin Yong Hwang; Seok Kyu Oh; Myeong Chan Cho; Kee Sik Kim; \\ Kyoung Tae Jeong; Myoung Yong Lee; Chong Jin Kim; Wook Sung Chung and other \\ Korea Acute Myocardial Infarction Registry Investigators*
}

\begin{abstract}
Background The aim of this study was to assess the impact of more aggressive pharmacological treatment on short-term clinical outcomes in patients with acute non ST-segment elevation myocardial infarction (NSTEMI) who do not undergo percutaneous coronary intervention (PCI).

Methods and Results The 924 NSTEMI patients treated with early conservative strategy $(69.2 \pm 12.5$ years, 637 males) in 50 hospitals that were high-volume centers with facilities for primary PCI were recruited to the Korean Acute Myocardial Infarction Registry (KAMIR) from November 2005 to August 2007. For all patients, the pharmacotherapy index based on the use of drugs during hospital stay was assessed (range of points 0-10). Primary endpoint was the combined in-hospital mortality and morbidity and major adverse cardiac events during 1 month of clinical follow-up. Of the patients, data from 847 who were followed-up for 1 month after discharge were analyzed. The rate of the primary endpoint decreased with an increase of the pharmacotherapy index and this result was similar in the low- and high-risk groups. In the multivariate analysis, low pharmacotherapy index ( $\leq 4$ points) was an independent predictor of the primary endpoint.

Conclusions More intensive pharmacological treatment may improve short-term clinical outcomes in acute NSETMI patients who do not undergo PCI. (Circ J 2008; 72: 1403-1409)
\end{abstract}

Key Words: Drugs; Myocardial infarction; Non ST-segment elevation; Prognosis

$\mathbf{T}$ The syndrome of non ST-segment elevation myocardial infarction (NSTEMI) accounts for much of the morbidity and mortality of cardiovascular disease! It is well known that percutaneous coronary intervention (PCI) is a most effective treatment of acute NSTEMI for restoring blood flow within the culprit artery? Recent studies indicate that a routine invasive approach for high-risk patients with NSTEMI yields improved outcomes compared with a conservative approach 3,4 However, there are many patients who can not undergo PCI because of poor general health (eg, severe renal or liver disease, gastrointestinal bleeding, malignant neoplasm, chronic obstructive lung disease) or admission to a facility that cannot perform PCI. In addition, NSTEMI can occur after episodes of hypotension, severe sepsis or anemia in critical care patients with

(Received January 28, 2008; revised manuscript received April 9, 2008; accepted April 16, 2008)

Heart Center of Chonnam National University Hospital, Gwangju, Republic of Korea

* Korea Acute Myocardial infarction Registry (KAMIR) Study Group of Korean Circulation Society members are listed in Appendix 1.

Mailing address: Young Keun Ahn, MD, PhD, FACC, FSCAI, Assistant Professor, Director of Cardiovascular Medicine, Heart Center of Chonnam National University Hospital, 8 Hak Dong, Dong Ku, Gwangju 501-757, Republic of Korea. E-mail: cecilyk@hanmail.net All rights are reserved to the Japanese Circulation Society. For permissions, please e-mail: cj@j-circ.or.jp acute non-cardiac illness 5,6 In these situations appropriate conservative treatment is important.

We conducted the present study to assess the impact of pharmacological treatment, with a focus on its influence on short-term clinical outcome in NSTEMI patients enrolled in the Korea Acute Myocardial Infarction Registry (KAMIR).

\section{Methods}

\section{Study Population and Study Design}

The KAMIR is a prospective, multicenter, observational registry designed to examine current epidemiology, in-hospital management and outcome of patients with acute myocardial infarction (MI) in Korea. A total of 50 university or community hospitals that are high-volume centers with facilities for PCI and on-site cardiac surgery were included in the KAMIR, which included 12,867 patients with acute MI admitted between November 2005 and August 2007. Of these, 4,059 patients with a final diagnosis of NSTEMI were enrolled in the present study and 1,124 patients $(69.2 \pm 12.5$ years, 637 males) were treated conservatively. Eligible patients had to have all 3 of the following: symptoms of ischemia that were increasing or occurred at rest, an elevated cardiac troponin I level $(\geq 2.0 \mathrm{ng} / \mathrm{ml})$ or creatine kinase-MB (19 U/L, exceeding twice the upper limit of normal); and ischemic changes as assessed by electrocardiography (ECG) (defined as ST-segment depression or 
Table 1 Baseline Clinical Characteristics and Hemodynamics of Patients Given Conservative Treatment

\begin{tabular}{|c|c|}
\hline & $n=847$ \\
\hline Age (years) & $69.0 \pm 12.5$ \\
\hline Male (\%) & $486(57.4)$ \\
\hline Body mass index $\left(\mathrm{kg} / \mathrm{m}^{2}\right)$ & $23.8 \pm 15.0$ \\
\hline \multicolumn{2}{|l|}{ Past history (\%) } \\
\hline Hypertension & $460(54.3)$ \\
\hline Diabetes mellitus & $307(36.2)$ \\
\hline Smoking & $369(43.6)$ \\
\hline Hyperlipidemia & $78(9.2)$ \\
\hline Family history of heart disease & $43(5.1)$ \\
\hline Prior angina & $90(10.6)$ \\
\hline Prior MI & $73(8.6)$ \\
\hline Prior PCI & $67(7.9)$ \\
\hline Prior coronary artery bypass graft & $20(2.4)$ \\
\hline \multicolumn{2}{|l|}{ Comorbidities } \\
\hline Cerebrovascular disease & $107(12.6)$ \\
\hline Peripheral vascular disease & $37(4.4)$ \\
\hline Severe renal disease & $65(7.7)$ \\
\hline Severe liver disease & $12(1.4)$ \\
\hline Pepticulcer disease & $8(0.9)$ \\
\hline Metastatic solid tumor & $20(2.4)$ \\
\hline Chronic obstructive lung disease & $39(4.6)$ \\
\hline \multicolumn{2}{|l|}{ Killip class } \\
\hline$I$ & $478(56.4)$ \\
\hline II & $146(17.2)$ \\
\hline III & $169(20.0)$ \\
\hline IV & $54(6.4)$ \\
\hline TIMI risk scores (points) & $3.3 \pm 1.6$ \\
\hline \multicolumn{2}{|l|}{ ECG findings at admission (\%) } \\
\hline Within normal limits & $160(18.9)$ \\
\hline ST-segment depression & $284(33.5)$ \\
\hline T-wave inversion & $303(35.8)$ \\
\hline \multicolumn{2}{|l|}{ Echocardiogram findings } \\
\hline $\operatorname{LVEF}(\%)$ & $50.5 \pm 31.9$ \\
\hline Total wall motion score & $20.5 \pm 10.9$ \\
\hline \multicolumn{2}{|l|}{ Laboratory findings } \\
\hline Creatine clearance $(\mathrm{ml} / \mathrm{min})$ & $60.9 \pm 55.4$ \\
\hline Creatine kinase (U/L) & $602.1 \pm 955.2$ \\
\hline Creatine kinase-MB (U/L) & $44.3 \pm 75.3$ \\
\hline Troponin I $(\mathrm{ng} / \mathrm{ml})$ & $16.8 \pm 40.6$ \\
\hline Troponin $T(\mathrm{ng} / \mathrm{ml})$ & $19.2 \pm 13.1$ \\
\hline Total cholesterol $(\mathrm{mg} / \mathrm{dl})$ & $173.1 \pm 49.4$ \\
\hline Triglyceride $(\mathrm{mg} / \mathrm{dl})$ & $114.9 \pm 73.0$ \\
\hline HDL-cholesterol $(\mathrm{mg} / \mathrm{dl})$ & $47.3 \pm 28.4$ \\
\hline LDL-cholesterol $(\mathrm{mg} / \mathrm{dl})$ & $110.0 \pm 45.9$ \\
\hline$h s-C R P(m g / d l)$ & $2.1 \pm 9.7$ \\
\hline NT-pro-BNP $(\mathrm{pg} / \mathrm{ml})$ & $6,491.7 \pm 1,027.2$ \\
\hline
\end{tabular}

MI, myocardial infarction; $P C I$, percutaneous coronary intervention; TIMI, Thrombolysis In Myocardial Infarction; LVEF, left ventricular ejection fraction; HDL, high-density lipoprotein; $L D L$, low-density lipoprotein; hs$C R P$, high-sensitive $C$-reactive protein; $N T$-pro- $B N P, N$-terminal pro-brain natriuretic peptide.

T-wave inversion $\geq 0.2 \mathrm{mV}$ in 2 contiguous leads).

We analyzed baseline demographic and clinical characteristics, relevant laboratory results, pharmacotherapy, mortality and morbidity during hospital stay. Killip class was evaluated at admission and the Thrombolysis In Myocardial Infarction (TIMI) risk score was calculated according to the guideline of Antman et $\mathrm{al}^{7}$ for each patient. ECG and echocardiography were performed in all patients. Major adverse cardiac events (MACE) during a 1-month clinical follow-up were evaluated. All data were recorded on a standardized, electronic, web page-based case report form (http://www. kamir.or.kr).

Cardiogenic shock was defined as reduced blood pressure (systolic blood pressure $<90 \mathrm{mmHg}$ or decrease in mean arterial pressure $>30 \mathrm{mmHg}$ ) and/or low urine output $\left(<0.5 \mathrm{ml} \cdot \mathrm{kg}^{-1} \cdot \mathrm{h}^{-1}\right)$, with a pulse rate $>60$ beats $/ \mathrm{min}$ with or without evidence of organ congestion? Baseline creatinine clearance was calculated using the Cockcroft-Gault formula taking into account age, sex and body weight? Renal insufficiency was defined as creatinine clearance $<60 \mathrm{ml} / \mathrm{min}$.

\section{Pharmacological Treatment}

For all patients, the pharmacotherapy index based on the use of pharmacological treatment regimens according to the attending doctor's decision during hospital stay was assessed. Each patient received 1 point for each of the following guideline-recommended drugs: aspirin, clopidogrel, platelet glycoprotein $\mathrm{IIb} / \mathrm{III} \mathrm{a}$ inhibitor, low-molecularweight or unfractionated heparin, $\beta$-blocker, angiotensinconverting enzyme inhibitor (ACEI)/angiotensin II receptor blocker (ARB), statin, cilostazol, nicorandil and nitrate; the range of points was from 0 to 10 . The drugs were administered intravenously for unfractionated heparin and glycoprotein IIb/IIIa inhibitor, subcutaneously for low-molecularweight heparin, and orally for the others.

\section{Primary Endpoint}

The primary endpoint was a composite of in-hospital death, complications, and MACE in the 1-month clinical follow-up. Death was defined as death from pump failure, mechanical complication (rupture of free wall, ventricular septal defect, mitral regurgitation etc), arrhythmia, sepsis, multi-organ failure, major bleeding, and non-cardiac origin. Cardiogenic shock, ventricular tachycardia and fibrillation (needed for anti-arrhythmic agent and/or defibrillation), atrioventricular blocker (needed for pacemaker), recurrent ischemia and MI, cerebrovascular accident, major bleeding, acute renal failure, multi-organ failure and sepsis were included as complications. MACE was defined as cardiac death, non-cardiac-death, MI, repeat PCI (target lesion or non-target lesion revascularization), and coronary artery bypass grafting.

\section{Statistical Analysis}

The SPSS for Windows, version 15.0 (Chicago, IL, USA) was used for all analyses. Continuous variables are presented as the mean value $\pm \mathrm{SD}$; comparisons were conducted by Student's t-test. Discrete variables are presented as percentages and relative frequencies; comparisons were made using chi-square statistics or Fisher's exact test as appropriate. Subgroups of high risk and low risk according to TIMI risk score, levels of high-sensitivity C-reactive protein (hs-CRP) and $\mathrm{N}$-terminal pro-brain natriuretic peptide (NT-pro-BNP), and age were analyzed to minimize the selection bias. Logistic regression analysis was performed to identify the independent predictors of the primary endpoint. The $95 \%$ confidence interval for the relative risk was calculated using standard errors from the Kaplan-Meier curve. A p-value $<0.05$ was considered statistically significant.

\section{Results}

\section{Study Population}

Baseline characteristics and hemodynamics of the 847 patients who were followed for 1 month after discharge are shown in Table 1 . The reasons why the patients could not undergo PCI were as follows: $766(90.4 \%)$ were poor candidates for coronary angiography or PCI, $42(4.9 \%)$ had failed PCI, 39 (4.6\%) refused PCI, 91 (10.7\%) were in 


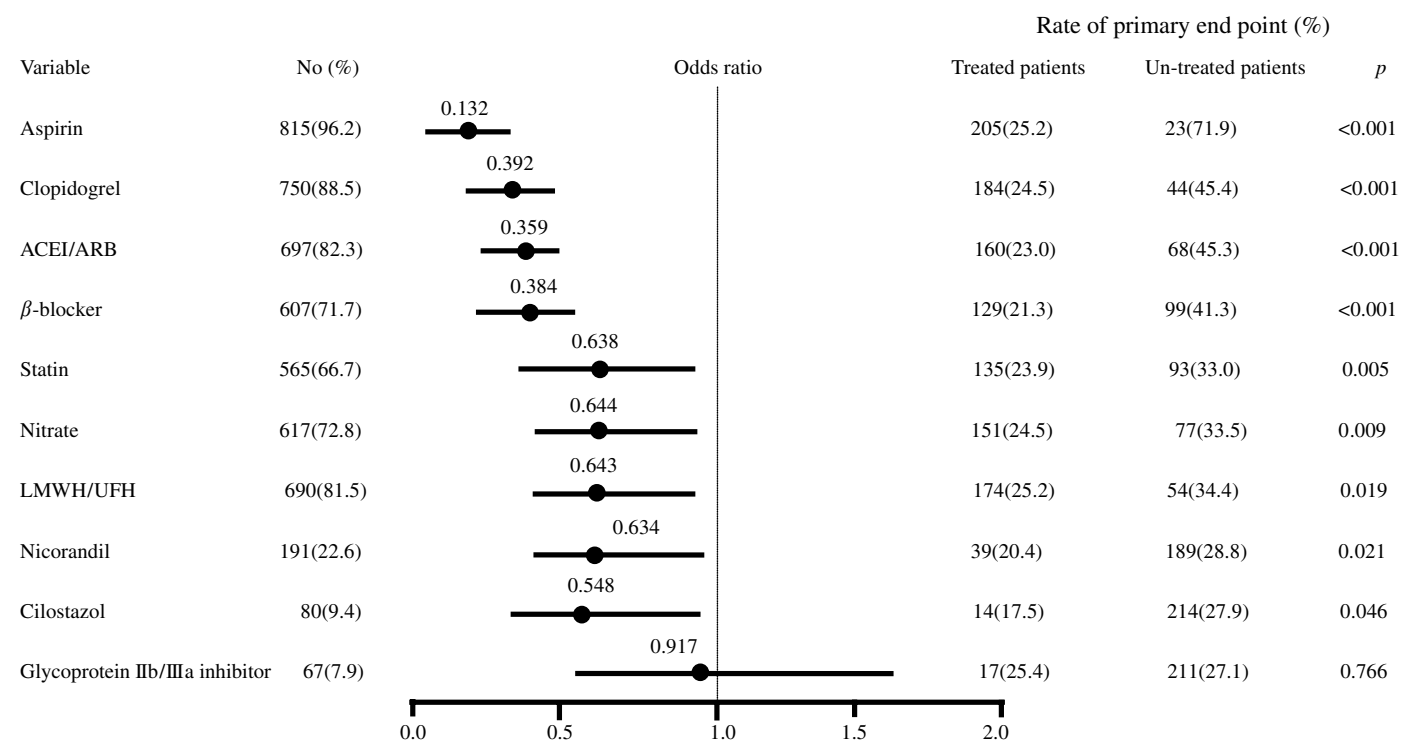

Fig 1. Estimated rates and odd ratios of the composite primary endpoint according to pharmacologic treatment with each drug. ACEI, angiotensin-converting enzyme inhibitor; ARB, angiotensin II receptor blocker; LMWH, low-molecularweight heparin; UFH, unfractionated heparin.

cardiogenic shock and $223(27.3 \%)$ had a high Killip class $(\geq \mathrm{III})$.

\section{Pharmacological Treatment}

The mean pharmacotherapy index was $6.0 \pm 1.7$. Most patients $(32.6 \%)$ had 7 points ( 0 points: $0.9 \% ; 1$ point: $0.8 \%$; 2 points: $2.0 \%$; 3 points: $5.8 \%$; 4 points: $7.7 \% ; 5$ points: 13.7\%; 6 points: $21.8 \%$; 7 points: $32.6 \%$; 8 points: $12.6 \%$; 9 points: $2.0 \%$; 10 points: $0.0 \%$ ). Patients with lower pharmacotherapy index values were more likely to have cardiogenic shock $(5.3 \pm 2.0$ with shock patients vs $6.1 \pm 1.6$ with non-shock patients, $\mathrm{p}<0.001)$. There was no significant difference in the pharmacologic index according to the presence of hypertension, diabetes or hyperlipidemia and no significant correlation with age, TIMI risk score, Killip class, ejection fraction or laboratory results.

\section{Primary Endpoints}

Total in-hospital mortality and morbidity for the 1,124 patients was $15.8 \%$ and total 1-month MACE, including in-hospital mortality and morbidity, was $26.9 \%$. Primary endpoints based on the drugs used during hospital stay are presented in Fig 1. In the univariate analysis, use of aspirin, clopidogrel, ACEI/ARB, $\beta$-blocker, statins, nitrate, heparin, nicorandil, and cilostazol led to a significant reduction of inhospital death and complications (odds ratio $=0.132,0.392$, $0.359,0.384,0.638,0.644,0.643,0.634,0.548$, respectively, p $<0.001,<0.001,<0.001,<0.001,0.005,0.009,0.019$, $0.021,0.046$ respectively; Table 2 ).

\section{Primary Endpoints in Subgroup Analysis}

The primary endpoints decreased with an increase of the pharmacotherapy index $(\mathrm{p}<0.001)$. In the subgroup analysis, the primary endpoints were significantly higher in the cardiogenic shock group than in the non-shock group (44.0\% vs $24.9 \%, \mathrm{p}<0.001)$. Higher pharmacologic index improved the clinical outcome in both the cardiogenic shock and nonshock group ( $\mathrm{p}=0.003,<0.001$, respectively) (Fig 2 ).

All patients were categorized into 3 groups according to TIMI risk score. A total of $37.4 \%$ were classified as low-
Table 2 Cumulative Rates of the Composite Primary Endpoint

\begin{tabular}{lc}
\hline \hline Outcome & $n=847$ \\
\hline In-hospital death (\%) & $96(11.3)$ \\
Pump failure & $56(6.6)$ \\
Multi-organ failure & $17(2.0)$ \\
Arrhythmia & $5(0.6)$ \\
Non-cardiac death & $4(0.5)$ \\
Sepsis & $4(0.5)$ \\
Mechanical complication & $2(0.2)$ \\
Major bleeding & $1(0.1)$ \\
In-hospital complications (\%) & $154(28.2)$ \\
Cardiogenic shock & $60(7.1)$ \\
Acute renal failure & $22(2.6)$ \\
Ventricular tachycardia & $21(2.5)$ \\
New onset heart failure & $18(2.1)$ \\
Cerebrovascular event & $16(1.8)$ \\
Multi-organ failure & $16(1.8)$ \\
Ventricular fibrillation & $15(1.8)$ \\
Atrial fibrillation & $11(1.3)$ \\
Major bleeding & $9(1.1)$ \\
Sepsis & $8(1.0)$ \\
Atrioventricular block & $3(0.4)$ \\
Recurrent ischemia & $1(0.1)$ \\
Re-infarction & $0(0.0)$ \\
MACE at 1-month clinical follow-up (\%) & $55(6.5)$ \\
Cardiac death & $28(3.3)$ \\
Non-cardiac death & $5(0.6)$ \\
ST-segment elevation MI & $7(0.8)$ \\
Non ST-segment elevation MI & $15(1.8)$ \\
PCI & $3(0.4)$ \\
Coronary bypass graft & $3(0.4)$ \\
\hline
\end{tabular}

MACE, major adverse cardiac events. Other abbreviations see in Table 1.

risk (0-2 points), $39.1 \%$ as intermediate-risk (3-4 points), and $23.5 \%$ as high-risk (5-7 points). The primary endpoints of each subgroup are presented in Fig 3. The tendency for the primary endpoints to decrease with the increase of the pharmacotherapy index were observed in all 3 risk groups (Fig 3) ( $\mathrm{p}=0.015,0.003,<0.001$, respectively).

The patients were classified by the levels of hs-CRP and NT-pro-BNP. The primary endpoints decreasing with the in- 


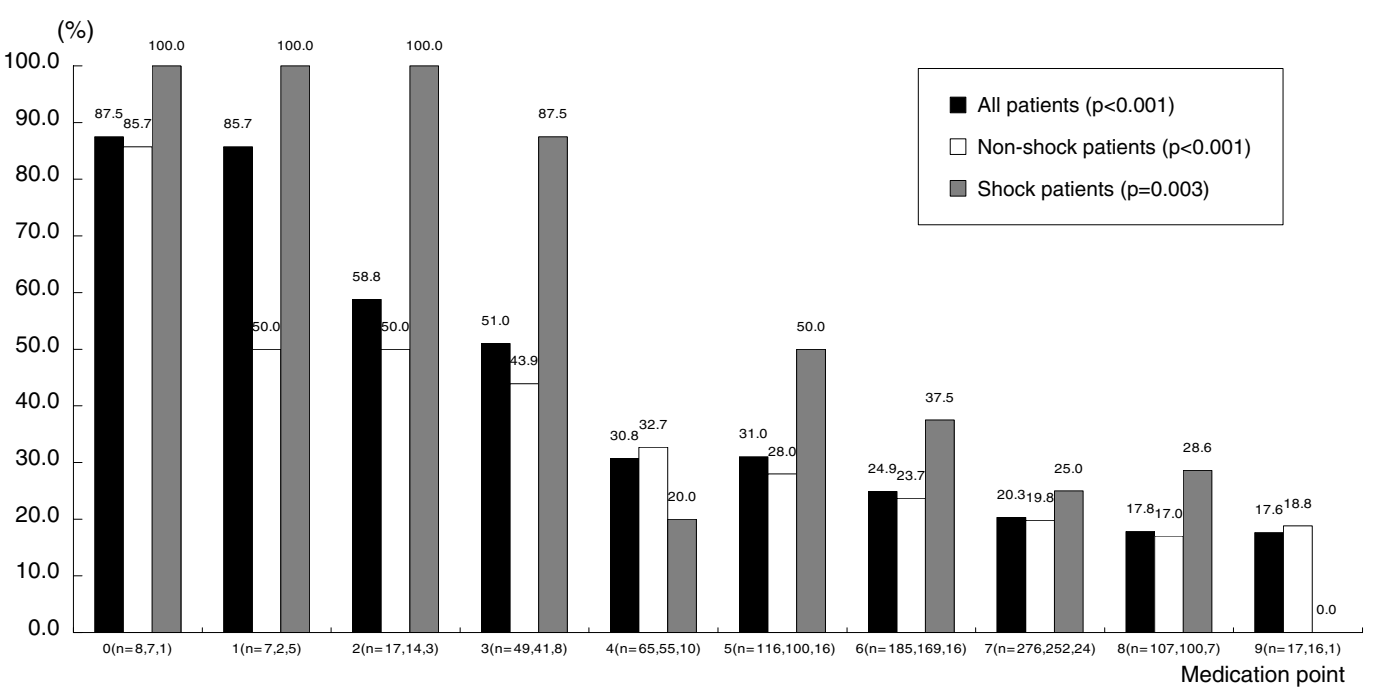

Fig 2. Primary endpoint for the conservative pharmacotherapy index value for all, non-shock and shock patients.

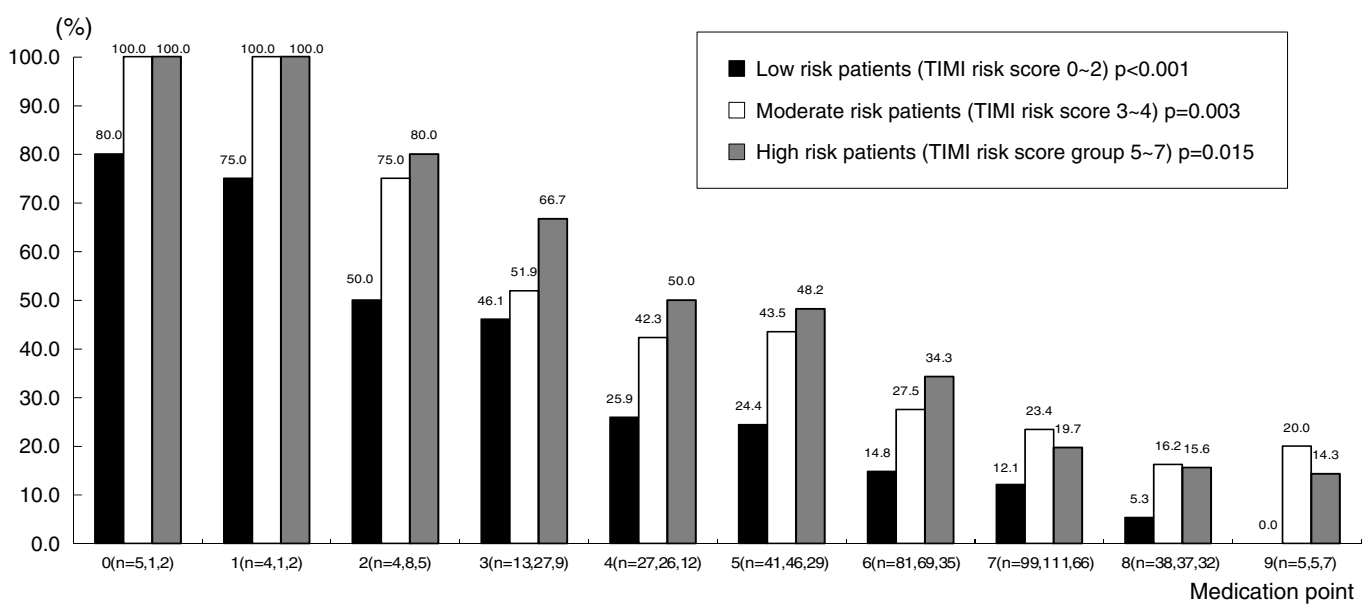

Fig 3. Primary endpoint according to the conservative pharmacotherapy index values for patients with high, moderate, and low Thrombolysis In Myocardial Infarction (TIMI) risk score.

crease of pharmacotherapy index occurred in both the lower hs-CRP group $(<0.875 \mathrm{mg} / \mathrm{dl})$ and higher hs-CRP group $(\geq 0.875 \mathrm{mg} / \mathrm{dl})(\mathrm{p}<0.001,0.001$, respectively) $(\mathrm{Fig} 4)$, and similarly in both the lower NT-pro-BNP $(<1,018 \mathrm{pg} / \mathrm{ml})$ and higher NT-pro-BNP group $(\geq 1,018 \mathrm{pg} / \mathrm{ml})(\mathrm{p}=0.015,0.002$, respectively) (Fig 5).

Subgroups were analyzed according to age. Overall, the primary endpoint was $35.5 \%$ in the elderly group $(\geq 75$ years, $\mathrm{n}=318$ ) and $21.7 \%$ in the non-elderly group ( $<75$ years, $\mathrm{n}=529$ ). The primary endpoint decreased with the increase of pharmacotherapy index in both the elderly and non-elderly groups (0 points: $100 \%, 86 \%$; 1 point: $100 \%, 80 \%$; 2 points: $80 \%, 50 \%$; 3 points: $54 \%, 48 \%$; 4 points: $46 \%, 24 \%$; 5 points: $37 \%, 25 \%$; 6 points: $36 \%, 20 \%$; 7 points: $28 \%$, $15 \%$; 8 points: $26 \%, 14 \%$; 9 points: $20 \%, 8 \%$; $\mathrm{p}=0.038, \mathrm{p}<$ 0.001 , respectively).

\section{Multivariate Analysis of In-Hospital Mortality and Morbidity}

In the multivariate regression analysis, independent predictors of in-hospital mortality and morbidity were high Killip score ( $\geq$ II), low pharmacotherapy index ( $\leq 4$ points), high levels of NT-pro-BNP $(\geq 1,018 \mathrm{pg} / \mathrm{ml})$, high levels of hs-CRP $(\geq 0.875 \mathrm{mg} / \mathrm{dl})$, and high TIMI risk score ( $\geq 5$ points) $(\mathrm{p}<0.001, \mathrm{p}<0.001, \mathrm{p}=0.011, \mathrm{p}=0.013, \mathrm{p}=0.033$, respectively) (Table 3 ).

\section{Discussion}

Acute coronary syndrome (ACS) is categorized into unstable angina, NSTEMI, and STEMI ${ }^{10}$ and the most effective treatment is revascularization using PCI ${ }^{11}$ The majority of recent studies are focused on invasive revascularization therapy for the management of ACS,2-14 but in certain situations appropriate medical treatment is also important. Our data support the benefit of more aggressive pharmacological treatment in patients with NSTEMI who do not or cannot undergo PCI. Regardless of the risk profile, the proposed pharmacotherapy index was shown to be an independent predictor of short-term clinical outcomes. For every unit increase in the pharmacotherapy index, the rate of incidence of the primary endpoint decreased. Even though patients with cardiogenic shock and in poor general condition might receive less pharmacologic treatment because of contra- 

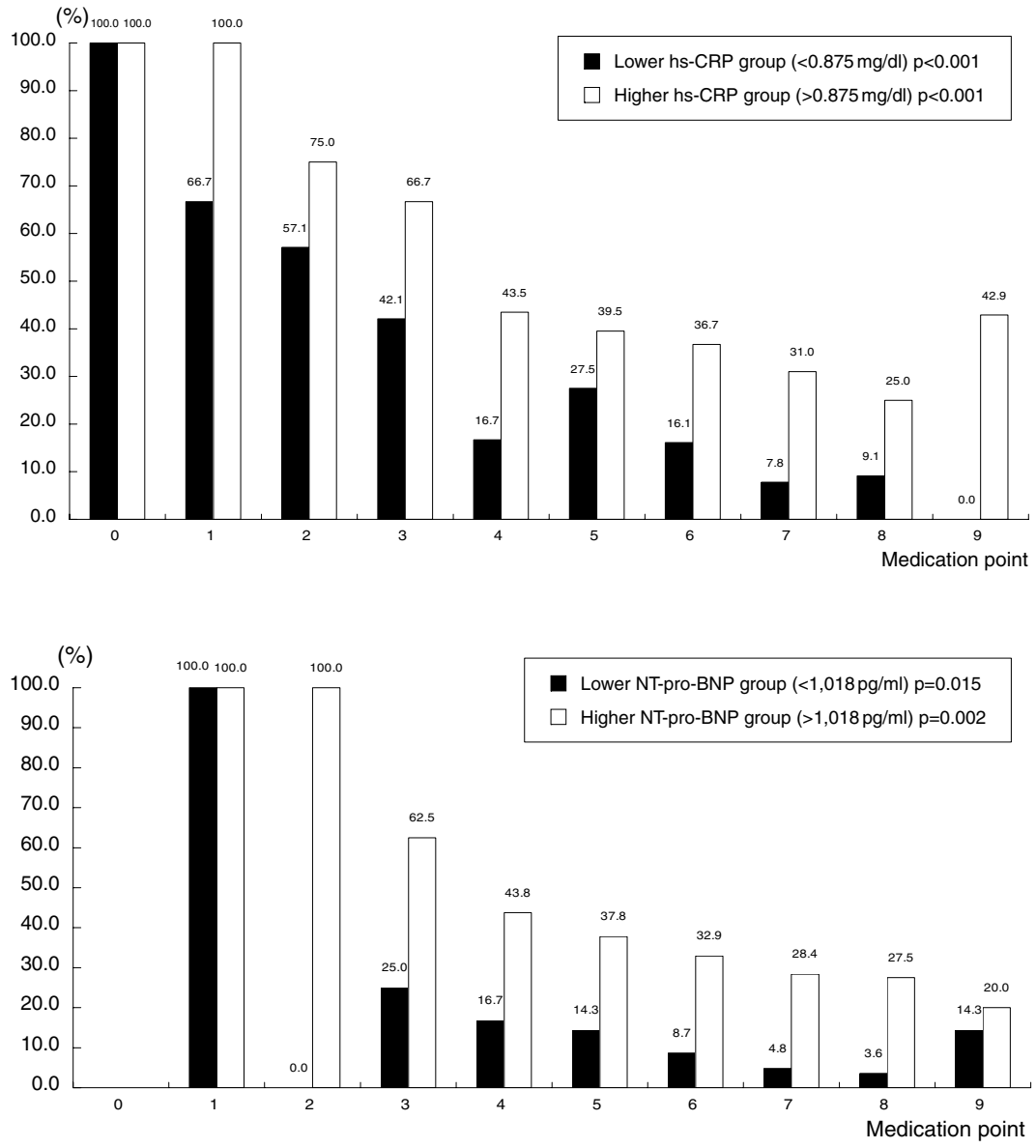

Fig 4. Primary endpoint according to the conservative pharmacotherapy index values for the levels of high-sensitivity C-reactive protein (hsCRP).

Fig 5. Primary endpoints according to the conservative pharmacotherapy index values for the levels of $\mathrm{N}$-terminal pro-brain natriuretic peptide (NT-pro-BNP).

Table 3 Multivariate Analysis of Predictors for Primary Endpoint

\begin{tabular}{lcccc}
\hline \hline & \multirow{2}{c}{$95 \%$ CI } & \multirow{2}{*}{ p value } \\
\cline { 3 - 4 } & & Lower & Upper & \\
\hline High Killip class $(\geq I I)$ & 2.68 & 1.831 & 3.924 & $<0.001$ \\
Low pharmacologic therapy index $(\leq 4$ points $)$ & 1.38 & 1.247 & 1.538 & $<0.001$ \\
High NT-pro-BNP $(\geq 1,018$ pg/ml) & 2.64 & 1.245 & 5.586 & 0.011 \\
High hs-CRP $(\geq 0.875 \mathrm{mg} / \mathrm{dl})$ & 2.19 & 1.177 & 4.097 & 0.013 \\
High TIMI risk score $(\geq 5$ points $)$ & 1.33 & 1.024 & 1.727 & 0.033 \\
Old age $(\geq 65$ years $)$ & 1.97 & 0.748 & 5.208 & 0.169 \\
Diabetes & 1.32 & 0.607 & 2.849 & 0.487 \\
High LDL $(\geq 100 \mathrm{mg} / \mathrm{dl})$ & 1.26 & 0.627 & 2.545 & 0.513 \\
Low ejection fraction $(50 \%)$ & 1.00 & 0.974 & 1.037 & 0.752 \\
High troponin I $(\geq 10 \mathrm{ng} / \mathrm{ml})$ & 1.00 & 0.995 & 1.005 & 0.999 \\
\hline
\end{tabular}

OR, odds ratio; CI, confidence interval. Other abbreviations see in Table 1.

indications of each drug, in the present study the results were similar for the non-shock and low-risk groups, as well as for the shock and high-risk groups.

Few clinical studies have investigated pharmacologic treatment for NSTEMI patients. Our results were comparable with those in previously reported clinical trials, $, 4,15$ The Malopolska Registry of Acute Coronary Syndromes (MRACS) registry data demonstrated that more aggressive pharmacological treatment may improve clinical outcome in patients with NSTE ACSs treated conservatively $!^{15}$ The CRUSADE (Can Rapid Risk Stratification of Unstable Angina Patients Suppress Adverse Outcomes with Early Implementation of the ACC/AHA Guidelines) registry data demonstrated that patients who presented with NSTEMI and did not receive guideline-recommended therapies had a higher mortality rate? Similarly, Gulati et al have shown that compliance with recommended guidelines results in fewer adverse cardiac events, independent of the risk stratification model4

There are different points between the present study and previous trials. First, the previous trials (especially MRACS registry study) were conducted without on-site invasive facilities and the study populations were not transferred to other hospitals for invasive treatment. Therefore, there are many selection biases of enrollment in the study group. Patients who did not require PCI because of low disease severity or who could not be transferred to another hospital because of poor general condition were likely to be enrolled. 
In contrast, our study was performed in high volume centers with facilities for PCI and on-site cardiac surgery, and thus the study population comprised patients who were not indicated for PCI. Therefore, the in-hospital mortality was higher than in previous trials and the selection bias was minimized. Second, our study used a 10-point scale. We incorporated recent advances in baseline medical therapy, such as the use of abciximab at the time of PCI, ${ }^{16-17}$ early use of clopidogrel ${ }^{18}$ intensive lipid-lowering therapy ${ }^{19,20}$ the use of ACEI/ARB ${ }^{21,22}$ and nitrate ${ }^{23}$ and intensive glucose control24 all of which have been shown to improve outcomes in patients with acute NSTEMI. In addition, cilostazol, a phosphodiesterase inhibitor and an antiplatelet agent with a positive chronotropic effect, was used, with an impact on left ventricular volume and function in acute MI25 Also nicorandil, which has a myocardial protective effect during PCI in patients with ACS because of its ischemic preconditioning effect ${ }^{2}{ }^{6}$ Third, previous trials evaluated only inhospital outcomes, whereas we evaluated not only in-hospital outcomes, but also MACE during a 1-month clinical follow-up. In our study, $55(6.5 \%)$ patients experienced a MACE in the 1-month clinical follow-up. Fourth, our study evaluated the effect of pharmacologic treatment according to risk stratification. Higher TIMI risk score and levels of hs-CRP27,28 and NT-pro-BNP29,30 are strong predictors of mortality in patients with ACS. In our study, patients were categorized into subgroups of high risk and low risk according to TIMI risk score and levels of hs-CRP and NTpro-BNP. Our results demonstrate that more aggressive pharmacologic treatment improved the clinical outcomes in both the high-risk and low-risk groups. Fifth, our study shows that the use of glycoprotein IIIb/IIIa inhibitors did not improve the clinical outcomes, although the rate of usage was low, presumably because of the Japanese medical insurance system ${ }^{31}$ However, studies of coincidence result have been reported; for example, the GUSTO IV-ACS investigators $^{32}$ reported that a platelet glycoprotein $\mathrm{IIb} / \mathrm{IIII}$ inhibitor (Abciximab) has the potential to deteriorate the early prognosis of patients with NSTEMI who did not undergo early PCI. Therefore, more randomized controlled trials are necessary. Sixth, thrombolytic therapy was not performed in our study because it is thought to be ineffective for NSTEMI, according to many studies and the 2007 guidelines of ACC/AHA, 33 so the present patients with NSTEMI was not treated by thrombolytic agents even though their PCI had failed.

Our proposed pharmacotherapy index can be interpreted as a predictor of favorable prognosis in patients with NSTEMI. On the other hand, patients with contraindications to the components of standard, guideline-recommended therapy (eg, with contraindications to antiplatelet drugs ${ }^{34,35}$ or to $\beta$-blockers) $)^{36}$ may have a higher risk of cardiovascular events in the short and long term. Recently, Peterson et al showed that adherence to guideline indices may be used as a surrogate marker in monitoring of hospitals' performance and for assessing overall quality of care $?^{37}$

\section{Study Limitations}

First, our study was a multicenter prospective registry study and not a randomized and controlled study. Second, medical therapy during hospitalization was not randomized and the drugs used before hospitalization were not evaluated. It is likely that, in some patients, aggressive medical therapy was not used because of their good clinical status. Moreover, patients were not screened for other contraindi- cations and indications for the use of each medication and the appropriateness of the dosage were not assessed. In particular, usage of ACEIs was not analyzed in the whole patient population, only in patients with left ventricular dysfunction or heart failure symptoms 38,39 Also, the route of administration of each drug was not unified, but that was unavoidable because that the marketed forms of the drugs was restricted. Third, the relative weight of each drug on outcome is probably not equal in the studied population. Usage of a diverse grading scale for each treatment could be justified. Finally, long-term clinical follow-up data were not available.

In conclusion, more intensive pharmacological treatment may improve short-term clinical outcome in NSETMI patients who are not indicated for PCI. Our findings support the need for more intensive pharmacological treatment of patients with NSTEMI.

\section{Acknowledgment}

This study was performed with the support of the Korean Circulation Society (KCS) in memorandum of the 50 th Anniversary of KCS and stem cell research program of the Ministry of Science \& Technology (grant M10641450001-06N4145-00110).

\section{References}

1. Jason WR, Eric DP, Anita YC, Matthew TR, Magnus O, Christopher PC, et al. Optimal timing of intervention in non-ST-Segment elevation acute coronary syndromes insights from the CRUSADE (Can Rapid risk stratification of Unstable angina patients Suppress ADverse outcomes with Early implementation of the ACC/AHA guidelines) Registry. Circulation 2005; 112: 3049-3057.

2. Silber S, Albertsson P, Aviles FF, Camici PG, Colombo A, Hamm C, et al. Guidelines for percutaneous coronary interventions: The Task Force for Percutaneous Coronary Interventions of the European Society of Cardiology. Eur Heart J 2005; 26: 804-847.

3. Ohman EM, Roe MT, Smith SC Jr, Brindis RG, Christenson RH, Harrington RA, et al. Care of non-ST-segment elevation patients: Insights from the CRUSADE national quality improvement initiative. Am Heart J 2004; 148: 34-39.

4. Gulati M, Patel S, Jaffe AS, Joseph AJ, Calvin JE Jr. Impact of contemporary guideline compliance on risk stratification models for acute coronary syndromes in The Registry of Acute Coronary Syndromes. Am J Cardiol 2004; 94: 873-878.

5. Maeder M, Fehr T, Rickli H, Ammann P. Sepsis-associated myocardial dysfunction: Diagnostic and prognostic impact of cardiac troponins and natriuretic peptides. Chest 2006; 129: 1349-1366.

6. Arlati S, Brenna S, Prencipe L, Marocchi A, Casella GP, Lanzani M, et al. Myocardial necrosis in ICU patients with acute non-cardiac disease: A prospective study. Intensive Care Med 2000; 26: 31-37.

7. Antman EM, Cohen M, Bernink PJ, McCabe CH, Horacek T, Papuchis G, et al. The TIMI risk score for unstable angina/non-ST elevation MI: A method for prognostication and therapeutic decision making. JAMA 2000; 284: 835-842.

8. Nieminen MS, Bohm M, Cowie MR, Drexler H, Filippatos GS, Jondeau G, et al. Executive summary of the guidelines on the diagnosis and treatment of acute heart failure: The Task Force on Acute Heart Failure of the European Society of Cardiology. Eur Heart J 2005; 26: 384-416.

9. Cockcroft DW, Gault MH. Prediction of creatinine clearance from serum creatinine. Nephron 1976; 16: 31-41.

10. Alpert JS, Thygesen K, Antman E, Bassand JP. Myocardial infarction redefined: A consensus document of The Joint European Society of Cardiology/American College of Cardiology Committee for the redefinition of myocardial infarction. J Am Coll Cardiol 2000; 36: 959-969.

11. Popma JJ, Suk J. Use of coronary revascularization in patients with unstable and non-ST-segment elevation acute myocardial infarction. Am J Cardiol 2001; 88: 25-29.

12. Bertrand ME, Simoons ML, Fox KA, Wallentin LC, Hamm CW, McFadden E, et al. Management of acute coronary syndromes in patients presenting without persistent ST-segment elevation. Eur Heart J 2003; 24: 1174-1175.

13. Winter RJ, Windhausen F, Cornel JH, Dunselman PH, Janus CL, Bendermacher PE, et al. Early invasive versus selectively invasive 
management for acute coronary syndromes. $N$ Engl J Med 2005; 353: $2714-2718$.

14. Alexander H, Fons W, Jan GP, Freek WA, Jan HC, Robbert J. The Invasive versus Conservative Treatment in Unstable coronary Syndromes (ICTUS) investigators. Lancet 2007; 369: 827-835.

15. Dziewierz A, Siudak Z, Rakowski T, Mielecki W, Giszterowicz D, Dubiel JS, et al. More aggressive pharmacological treatment may improve clinical outcome in patients with non-ST-elevation acute coronary syndromes treated conservatively. Coron Artery Dis 2007; 18: 299-303.

16. Kim JH, Jeong MH, Rhew JY, Lim JH, Yun KH, Kim KH, et al. Long-term clinical outcomes of platelet glycoprotein IIIb/IIIa inhibitor combined with low molecular weight heparin in patients with acute coronary syndrome. Circ J 2005; 69: 159-164.

17. Valencia R, Price MJ, Sawhney N, Lee SS, Wong GB, Gollapudi RR, et al. Efficacy and safety of triple antiplatelet therapy with and without concomitant anticoagulation during elective percutaneous coronary intervention (the REMOVE Trial). Am J Cardiol 2007; 100: $1099-1102$

18. Biondi-Zoccai GG, Lotrionte M, Agostoni P, Valgimigli M, Abbate A, Sangiorgi G, et al. Benefits of clopidogrel in patients undergoing coronary stenting significantly depend on loading dose: Evidence from a meta-regression. Am Heart J 2007; 153: 587-593.

19. Cannon CP, Braunwald E, McCabe CH, Rader DJ, Rouleau JL, Belder R, et al. Intensive versus moderate lipid lowering with statins after acute coronary syndromes. N Engl J Med 2004; 350: $1495-$ 1504 .

20. Miyauchi K, Kimura T, Morimoto T, Nakagawa Y, Yamagishi M, Ozaki Y, et al. Japan Assessment of Pitavastatin and AtorvastatiN in Acute Coronary Syndrome (JAPAN-ACS): Rationale and design. Circ J 2006; 70: $1624-1628$.

21. Savoye C, Equine O, Tricot O, Nugue O, Segrestin B, Sautiere K, et al. Left ventricular remodeling after anterior wall acute myocardial infarction in modern clinical practice (from the REmodelage VEntriculaire [REVE] study group). Am J Cardiol 2006; 98: $1144-$ 1149 .

22. Dagenais GR, Pogue J, Fos K, Simoons ML, Yusuf S. Angiotensinconverting-enzyme inhibitors in stable vascular disease without left ventricular systolic dysfunction or heart failure: A combined analysis of three trials. Lancet 2006; 368: 581-588.

23. Kojima S, Matsui K, Sakamoto T, Ishihara M, Kimura K, Miyazaki $\mathrm{S}$, et al. Long-term nitrate therapy after acute myocardial infarction does not improve or aggravate prognosis. Circ J 2007; 71: 301 - 307 .

24. Iijima R, Nakajima R, Sugi K, Nakamura M. Improvement of postprandial hyperglycemia has a positive impact on epicardial flow of entire coronary tree in acute coronary syndromes patients. Circ J 2007; 71: 1079-1085.

25. Lee SH, Choi SH, Choi S, Jung JH, Lee N, Choi YJ, et al. Impact of chronotropic effect of cilostazol after acute myocardial infarction: Insights from change in left ventricular volume and function. Circ $J$ 2007; 71: 106-111

26. Kim JH, Jeong MH, Yun KH, Kim KH, Kang DK, Hong SN, et al. Myocardial protective effects of nicorandil during percutaneous coronary intervention in patients with unstable angina. Circ J 2005; 69: $306-310$

27. Sukhija R, Fahdi I, Garza L, Fink L, Scott M, Aude W, et al. Inflammatory markers, angiographic severity of coronary artery disease, and patient outcome. Am J Cardiol 2007; 99: 879-884.

28. Kim H, Yang DH, Park Y, Han J, Lee H, Kang H, et al. Incremental prognostic value of $\mathrm{C}$-reactive protein and $\mathrm{N}$-terminal proB-type natriuretic peptide in acute coronary syndrome. Circ J 2006; 70: $1379-1384$

29. Hong SN, Ahn Y, Yoon NS, Lee KH, Kim YS, Hwang SH, et al.
Usefulness of serum $\mathrm{N}$-terminal pro-brain natriuretic peptide to predict in-stent restenosis in patients with preserved left ventricular function and normal troponin I levels. Am J Cardiol 2007; 99: 10511054.

30. Ogawa A, Seino Y, Yamashita T, Ogata K, Takano T. Difference in elevation of N-terminal pro-BNP and conventional cardiac markers between patients with ST elevation vs non-ST elevation acute coronary syndrome. Circ J 2006; 70: 1372-1378.

31. Kim W, Jeong MH, Kim KH, Park JC, Lee SH, Rhew JY, et al. The rescue use of a platelet glycoprotein IIb/IIIa receptor blocker (Abciximab; Reo-Pro ${ }^{\circledR}$ ) in high-risk patients with acute myocardial infarction underwent percutaneous coronary intervention. Korean Circ J 2001; 31: 492-499.

32. Simoons ML, GUSTO IV-ACS Investigators. Effect of glycoprotein $\mathrm{IIb} / \mathrm{III}$ a receptor blocker abciximab on outcome in patients with acute coronary syndromes without early coronary revascularisation: The GUSTO IV-ACS randomised trial. Lancet 2001; 357: 1915-1924.

33. Anderson JL, Adams CD, Antman EM, Bridges CR, Califf RM, Casey DE, et al. ACC/AHA 2007 guidelines for the management of patients with unstable angina/non ST-elevation myocardial infarction: A report of the American College of Cardiology/American Heart Association Task Force on Practice Guidelines. Circulation 2007; 116: e148-e304.

34. Valencia R, Price MJ, Sawhney N, Lee SS, Wong GB, Gollapudi RR, et al. Efficacy and safety of triple antiplatelet therapy with and without concomitant anticoagulation during elective percutaneous coronary intervention (the REMOVE Trial). Am J Cardiol 2007; 100: $1099-1102$

35. Schneider DJ, Sobel BE. Conundrums in the combined use of anticoagulants and antiplatelet drugs. Circulation 2007; 116: 305-315.

36. Bentura HO. Benefits of inpatient initiation of beta-blockers. Am Heart J 2004; 148: 944-950.

37. Peterson ED, Roe MT, Mulgund J, DeLong ER, Lytle BL, Brindis $\mathrm{RG}$, et al. Association between hospital process performance and outcomes among patients with acute coronary syndromes. JAMA 2006; 295: 1912-1920.

38. Setoguchi S, Glynn RJ, Avorn J, Levin R, Winkelmayer WC. Tenyear trends of cardiovascular drug use after myocardial infarction among community-dwelling persons $\geq 65$ years of age. Am J Cardiol 2007; 100: $1061-1067$.

39. Hong YJ, Jeong MH, Lim SY, Lee SR, Hong SN, Kim KH, et al. The long-term clinical outcomes of combination therapy with angiotensin II type I receptor blocker and simvastatin after percutaneous coronary intervention. Korean Circ J 2005; 35: 877-882.

\section{Appendix 1}

Korea Acute Myocardial Infarction (KAMIR) Investigators

Myung Ho Jeong, MD; Young Keun Ahn, MD; Shung Chull Chae, MD; Jong Hyun Kim, MD; Seung Ho Hur, MD; Young Jo Kim, MD; In Whan Seong, MD; Dong Hoon Choi, MD; Jei Keon Chae, MD; Taek Jong Hong, MD; Jae Young Rhew, MD; Doo Il Kim, MD; In Ho Chae, MD; Jung Han Yoon, MD; Bon Kwon Koo, MD; Byung Ok Kim, MD; Myoung Yong Lee, MD; Kee Sik Kim, MD; Jin Yong Hwang, MD; Myeong Chan Cho, MD; Seok Kyu Oh, MD; Nae Hee Lee, MD; Kyoung Tae Jeong, MD; Seung Jea Tahk, MD; Jang Ho Bae, MD; Seung Woon Rha, MD; Keum Soo Park, MD; Chong Jin Kim, MD; Kyoo Rok Han, MD; Tae Hoon Ahn, MD; Moo Hyun Kim, MD; Ki Bae Seung, MD; Wook Sung Chung, MD; Ju Young Yang, MD; Chong Yun Rhim, MD; Hyeon Cheol Gwon, MD; Seong Wook Park, MD; Young Youp Koh, MD; Seung Jae Joo, MD; Soo Joong Kim, MD; Dong Kyu Jin, MD; Jin Man Cho, MD; Yang Soo Jang, MD; Jeong Gwan Cho, MD; Seung Jung Park, MD. 